\title{
Chromosomal characterization of Umblachery breed of cattle (Bos indicus) - a famous South Indian breed of Tamilnadu, India
}

\author{
P. Kumarasamy*, S. N. Sivaselvam, R. Rajendran, P. Thangaraju and \\ A. Mahalinga Nainar \\ Department of Animal Genetics and Breeding, Madras Veterinary College, \\ Tamilnadu Veterinary and Animal Sciences University, Chennai, Tamilnadu, India. \\ pkumarasamy@rediffmail.com
}

\begin{abstract}
Umblachery breed is an excellent draught cattle of Tamilnadu, noted for its strength and sturdiness especially used in the marshy fields for wed ploughing. Several genetic markers have been used for identification of farm animals. The present study was undertaken to characterize the Umblachery breed with chromosomes. The diploid chromosome number in Umblachery cattle was $2 n=60$ comprising of 29 pairs of autosomes and one pair of sex chromosomes. All autosomes are acrocentric, the $\mathrm{X}$ - chromosome is submetacentric and $\mathrm{Y}$ chromosome is acrocentric. C-banding in Umblachery cattle was showed all autosomes with darkly stained centromere but the sex chromosomes were found to be C-band negative.

Key words: Chromosomal characterization, Umblachery cattle.

Introduction
\end{abstract}

The population explosion and a poor distribution of food are among the world's greatest problems today. Animals throughout the world supply human beings with milk, meat, egg, draft power, transportation, hides, fertilizer and many other useful products. Farm animal contribution to mankind in developing or under developed countries in the world is immense. Tamilnadu is the home of a few well-known draught breeds of cattle, such as Kangayam, Umblachery, Bargur, Alambadi and Pulikulam. Umblachery breed is one among the famous draught breeds of Tamilnadu. It is also known by the synonyms Mottai madu, Molai madu, Jathi madu and Therkathi madu. The Umblachery is a medium sized draught type cattle. It is strong and active with compact body and short legs.

The calves of the breed are red or brown in colour at birth. The red colour begins to change to grey at three to four months of age. Total grey colour is generally attained at six to eight months of age. In some animals, total grey colour is attained even at the age of one year. Genetic markers facilitate the "tagging" of individual genes or small chromosome segments containing genes, which influence the trait of interest. Chromosomal studies are mainly useful for gene mapping, identification of markers etc. The chromosomal studies in Umblachery breed of cattle are not available. Hence, the present study was undertaken to characterise the breed by cytogenetic parameters.

\section{Materials and methods \\ Collection of blood samples}

Blood samples from 30 Umblachery cattle from different villages in Thiruvarur district collected in a vacutainer with heparin sodium, transported to the Laboratory in ice were cultured within $16 \mathrm{hrs}$.

\section{Culture technique}

The culture technique was carried out as per Moorehead et al. (1960) with minor modification. RPMI-1640 was used as the cell culture medium. Benzyl penicillin and streptomycin sulphate were added at $100 \mathrm{IU} / \mathrm{ml}$ and $100 \mu \mathrm{g} / \mathrm{ml}$ respectively. Autologous plasma or foetal calf serum $2 \mathrm{ml}, 0.5 \mathrm{ml}$ of whole blood and $0.1 \mathrm{ml}$ of phytohaemaglutinin (PHA-M) were added to $8 \mathrm{ml}$ of culture medium. The tubes were incubated at $37^{\circ} \mathrm{C}$ for $72 \mathrm{hrs}$. Colchicine $(0.1 \mu \mathrm{g} / \mathrm{ml})$ was added one hour before harvest of cultures. The cells were subjected to hypotonic treatment $(0.075 \mathrm{M} \mathrm{KCl})$ for $30 \mathrm{~min}$ at $37^{\circ} \mathrm{C}$. The supernatant was removed after centrifugation at $1000 \mathrm{rpm}$ for $10 \mathrm{~min}$ leaving the cell button. Then the cells were fixed in Carnoy's fluid (3:1 Methanol: Acetic acid). The cell fixing procedure was repeated 2 to 3 times and the tubes were placed at $4^{\circ} \mathrm{C}$ overnight. Chromosome spreads were prepared and stained with 4 per cent Giemsa for 20-25 minutes. The chromosomal spreads were photographed; the length of chromosomes was measured with Vernier calliper. The per cent relative length of individual chromosome was calculated. The chromosomes were paired in the order of descending lengths for karyotyping.

\section{$C$ banding}

The slides with good metaphase spreads were aged at room temperature for 10 days. The aged slides were subjected to C-banding studies as per the technique of Sumner (1972) with slight modification. The slides were immersed in a coplin jar containing one per cent Barium hydroxide solution at $50^{\circ} \mathrm{C}$ for 20 minutes. Then the slides were washed in distilled water and immersed in $2 X$ SSC solutions for one hour at $60^{\circ} \mathrm{C}$. The slides were finally washed in triple glass distilled water and counterstained with 4 per cent Giemsa in phosphate buffer $(\mathrm{pH} \mathrm{6.8)}$ for 90 minutes showed band pattern during analysis. 


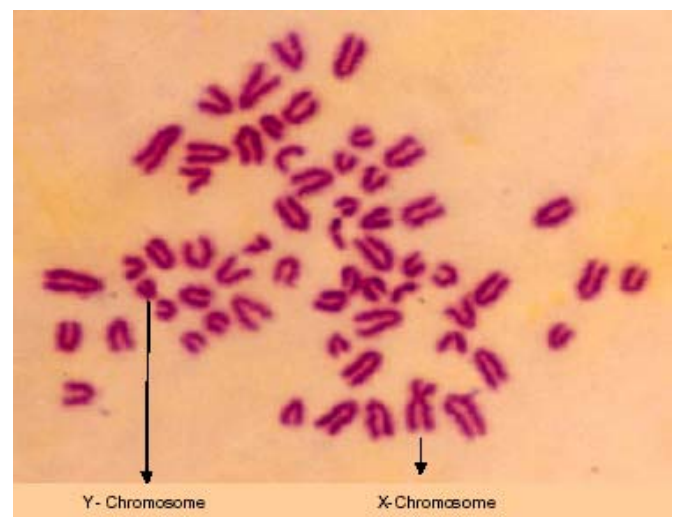

Fig. 1. Mitotic metaphase chromosomal spread of Umblachery bull.

\section{Results and discussion}

The slides with good metaphase spreads were photographed (Fig.1 \& 2) and counted for model chromosomal number. The modal chromosome number in Umblachery cattle was $60(2 n=60)$, which include 29 pairs of autosomes and one pair of sex chromosomes. The normal karyotype of Umblachery male animal (Fig.3) shows, all the autosomes were acrocentric but the X-chromosome was submetacentric and Y-chromosome was small acrocentric. This result was in agreement with Kieffer and Cartwright (1968) and Di Berardino et al. (1990). Benjamin and Bhatt (1977) also reported that Ychromosome was acrocentric in zebu (Hariana) cattle, but they did not report the size of the Y-chromosome. The per cent relative length of chromosomes in Umblachery cattle was calculated and presented in the Table.1. The idiogram was prepared based on the per



Fig, 3. Normal karyotype of Umblachery bull $(2 n=60)$

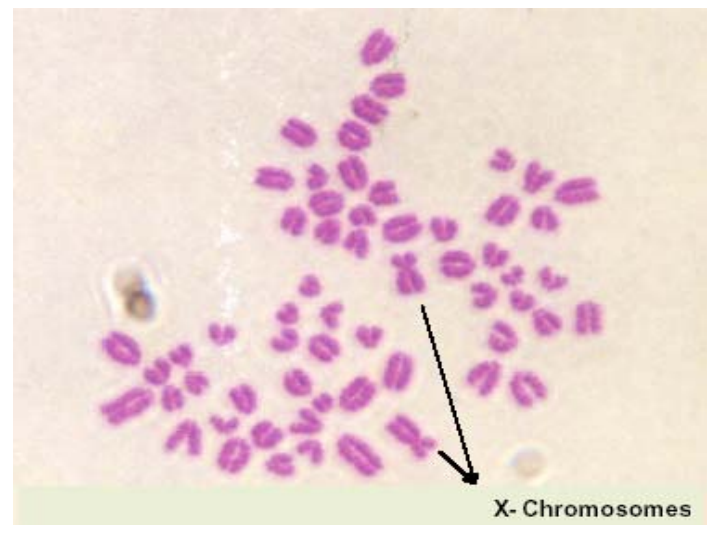

Fig. 2. Mitotic metaphase chromosomal spread of Umblachery cow.

cent relative length of the chromosomes and given in Fig.4. According to the per cent relative length, the first pair was the largest acrocentric with a relative length of 4.637 and that of X-chromosome was 5.002. The arm ratio and centromeric index of $X$ chromosome were 2.035 and 0.317 respectively. The per cent relative length of $\mathrm{Y}$-chromosome was 1.953.

The C-banded metaphase chromosomal spreads exhibited all the autosomes with distinct staining of heterochromatin in centromeric region, where as the $\mathrm{X}$ - and $\mathrm{Y}$ - chromosomes were uniformly stained. The chromosomes 7, 12, 14 and 15 had greater heterochromatin content than the other autosomes, the results were in agreement with Rasool et al. (1995).

\section{Conclusion}

The modal diploid chromosome number in Umblachery cattle was found to be $2 n=60$, comprising of 29 pairs of autosomes and a pair of sex chromosome. All the autosomes were acrocentric in nature. The X-chromosome was submetacentric, the largest chromosome in the complement. The Y-chromosome was small acrocentric, which resembled $28^{\text {th }}$ pair of chromosomes. The morphometric characteristics of chromosomes were studied and an idiogram was prepared. The per cent relative length of autosomes ranged from 4.637 to 1.85 . The relative length of X-chromosome was 5.002 and $\mathrm{Y}$ chromosome was 1.953 per cent. The arm ratio and centromeric index of $\mathrm{X}$-chromosome were 2.035 and 0.317 respectively. The C-banding showed staining of all the autosomes in centromeric region, where as the $\mathrm{X}$ - and $\mathrm{Y}$ chromosomes were uniformly stained. The chromosomes 7, 12, 14 and 15 had greater heterochromatin content than the other autosomes. 
Indian Journal of Science and Technology

Acknowledgement

The authors thank the ICAR, New Delhi and NBAGR, Karnal for funding the Core Laboratory project.

References

1. Benjamin BR and Bhat PN (1977) Chromosomal studies on cattle with special reference to cross-breeding. Indian J. Animal Sci. 47, 4-7.

2. Di Berardino D, Hayes $H$, Fries $R$ and Long S (1990) International System for Cytogenetic Nomenclature of Domestic Animals (ISCNDA, 1989). Cytogen. Cell Gen. 53, 65.

3. Kieffer MN and Cartwright TC (1968) Sex chromosome polymorphism in domestic cattle. J. Heredity. 59, 35-36.

4. Moorehead PS, Nowell PC, Mellman WJ, Batthips DM and Hungerford DA (1960) Chromosome preparation of leucocytes cultured from human peripheral blood. Exptl. Cell Res. 20, 613-616.

5. Rasool TT, Bhar PP, Dechamma HJ Kumar S and Bhat PN (1995) Studies on the heterochromatin content among zebu and tarus cattle detected by Cbanding technique. Indian J. Dairy Biosci. 6, 34-38.

6. Sumner AT (1972) A simple technique for demonstrating centromeric heterochromatin. Exptl. Cell Res. 83, 438-442. http://www.indjst.org

Vol.1 No 6 (Nov. 2008)

Table 1. Morphometric characteristics of Umblachery cattle chromosomes.

\begin{tabular}{|c|c|c|c|}
\hline $\begin{array}{c}\text { Chromosome } \\
\text { Number }\end{array}$ & $\begin{array}{c}\text { Relative Length } \\
(\%)\end{array}$ & $\begin{array}{c}\text { Arm ratio } \\
(\mathrm{q} / \mathrm{p})\end{array}$ & $\begin{array}{c}\text { Centromeric } \\
\text { Index }(p / p+q)\end{array}$ \\
\hline 1 & $4.637+0.063$ & -- & -- \\
\hline 2 & $4.486+0.034$ & -- & -- \\
\hline 3 & $4.390 \pm 0.015$ & -- & -- \\
\hline 4 & $4.330 \pm 0.026$ & -- & -- \\
\hline 5 & $4.222 \pm 0.043$ & -- & -- \\
\hline 6 & $4.083 \pm 0.059$ & -- & -- \\
\hline 7 & $3.936 \pm 0.036$ & -- & -- \\
\hline 8 & $3.848 \pm 0.038$ & -- & -- \\
\hline 9 & $3.733 \pm 0.015$ & -- & -- \\
\hline 10 & $3.678 \pm 0.048$ & -- & -- \\
\hline 11 & $3.610 \pm 0.006$ & -- & -- \\
\hline 12 & $3.568 \pm 0.008$ & -- & -- \\
\hline 13 & $3.453 \pm 0.058$ & -- & -- \\
\hline 14 & $3.198+0.008$ & -- & -- \\
\hline 15 & $3.138 \pm 0.010$ & -- & -- \\
\hline 16 & $3.086 \pm 0.022$ & -- & -- \\
\hline 17 & $3.005 \pm 0.029$ & -- & -- \\
\hline 18 & $2.912 \pm 0.034$ & -- & -- \\
\hline 19 & $2.861 \pm 0.037$ & -- & -- \\
\hline 20 & $2.770 \pm 0.062$ & -- & -- \\
\hline 21 & $2.712 \pm 0.060$ & -- & -- \\
\hline 22 & $2.557 \pm 0.060$ & -- & -- \\
\hline 23 & $2.445+0.025$ & -- & -- \\
\hline 24 & $2.272 \pm 0.023$ & -- & -- \\
\hline 25 & $2.201 \pm 0.014$ & -- & -- \\
\hline 26 & $2.133 \pm 0.027$ & -- & -- \\
\hline 27 & $2.012 \pm 0.019$ & -- & -- \\
\hline 28 & $1.910 \pm 0.028$ & -- & -- \\
\hline 29 & $1.850 \pm 0.027$ & -- & -- \\
\hline$x$ & $5.002 \pm 0.114$ & $\begin{array}{c}2.035 \pm \\
0.013\end{array}$ & $0.317 \pm 0.007$ \\
\hline Y & $1.953+0.021$ & -- & -- \\
\hline
\end{tabular}

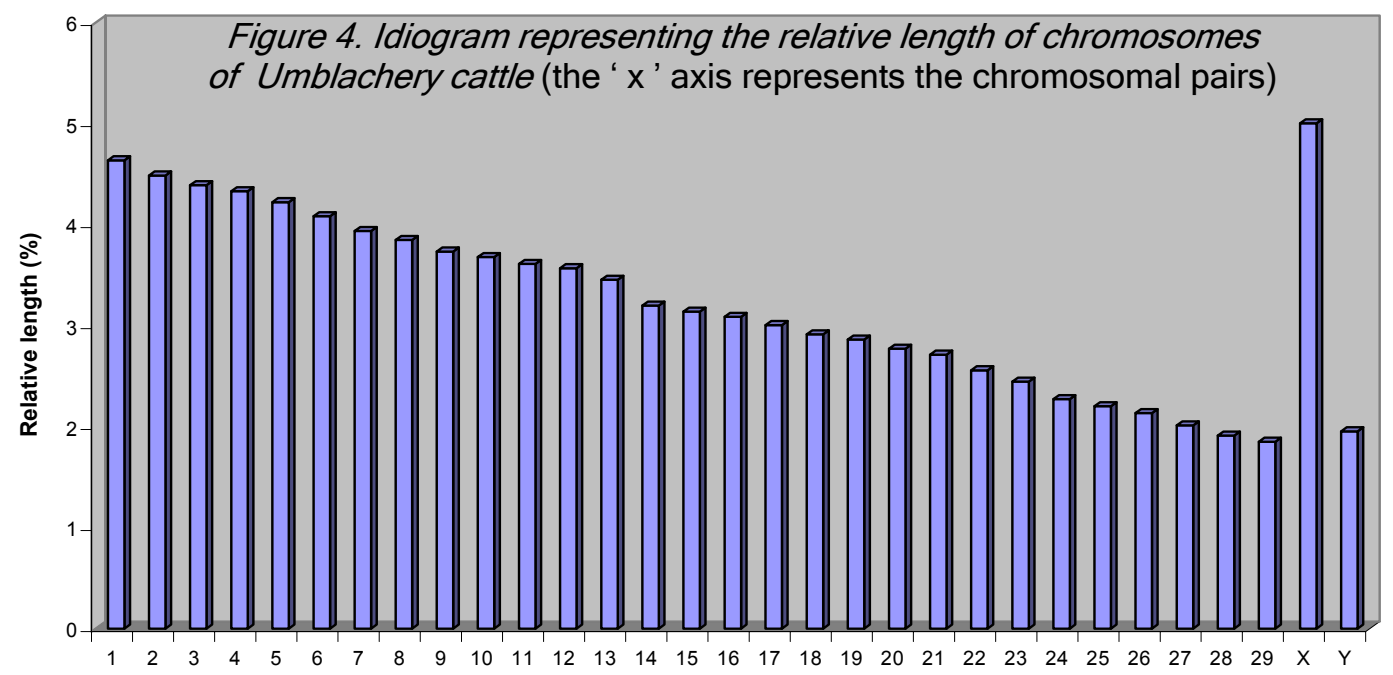

